\title{
Estimation of serum gentamicin by quenching fluoroimmunoassay
}

\author{
ElizABETH J. SHAW, R. A. AMINA WATSON, J. LANDON, AND D. S. SMITH \\ From the Departments of Medical Microbiology and Chemical Pathology, St. Bartholomew's Hospital \\ Medical College, London EC1, and Technicon Methods and Standards Laboratory, \\ Bartholomew Close, London EC1
}

SUMMARY A new type of non-isotopic immunoassay, applied to the determination of serum gentamicin, is reported. The method is based on partial quenching of fluorescence observed when fluorescein-labelled gentamicin is bound by anti-gentamicin serum. The fluorescence intensity of the labelled gentamicin in an unseparated immunoassay incubation mixture therefore serves to indicate the extent of binding, which is related to the amount of competing unlabelled gentamicin present. Precision and accuracy are shown to be similar to those of the best existing methods for gentamicin, while the new assay is more rapid and technically simpler, and avoids the use of expensive radiochemicals with their attendant health hazard. Assays of patient samples correlate with established bioassay and polarisation fluoroimmunoassay methods.

Gentamicin is a valuable and widely used antibiotic, but in systemic therapy the range between therapeutic and potentially toxic serum levels is narrow (Reeves, 1974). For this reason gentamicin assays are performed more frequently than for any other antibiotic (Reeves and Bywater, 1975).

At present the common assay method is the plate diffusion bioassay which, although simple and inexpensive, is slow and, in many laboratories, inaccurate (Reeves and Bywater, 1975). The shortcomings of the plate technique have prompted the development of alternative methods. The urease method (Noone et al., 1971) is founded on a simple principle, but its reliability remains in some doubt (Reeves, 1972; Phillips et al., 1974; Reeves and Bywater, 1975). Radioenzymatic methods based on adenylylation (Smith et al., 1972; Phillips et al., 1974; ten Krooden and Darrell, 1974) or acetylation (Broughall and Reeves, 1975; Stevens et al., 1975) of gentamicin, and radioimmunoassays employing tritiated (Mahon et al., 1973; Berk et al., 1974; Stevens et al., 1975) or ${ }^{125}$ I-labelled (Broughton and Strong, 1976; Watson et al., 1976b) gentamicin can be precise and accurate, but these techniques

${ }^{1}$ Correspondence and requests for reprints to: Dr. D. S. Smith, Technicon Methods and Standards Laboratory, 54 Bartholomew Close, London EC1A 7HL

Received for publication 18 November 1976 require skilled manipulations in effecting a crucial separation step, involve a radiation hazard, and suffer from the high cost of the necessary radiochemicals, associated reagents, and capital equipment.

A polarisation fluoroimmunoassay for gentamicin, based on detection of the extent of antibody binding of fluorescein-labelled gentamicin by measurement of fluorescence polarisation, has been developed (Watson et al., 1976a). Compared with radio- 3 . immunoassay, this method benefits from non- $\delta$ radioactive, easily prepared, and stable labelled material, and from the absence of a separation step, 을 which simplifies and speeds the assay procedure. However, an obstacle to the widespread use of this technique is that a specialised polarisation fluorimeter is required if measurements are to be made suffi- $\sigma$ ciently rapidly and conveniently for most routine $N$ purposes.

We now report a new fluoroimmunoassay method 0 for gentamicin which exploits the observation that the fluorescence of fluorescein-labelled gentamicin $\frac{0}{\Phi}$ is partially quenched upon binding by anti-genta- $\stackrel{\infty}{?}$ micin serum. When an appropriate amount of $\square$ antiserum is added to a mixture of unlabelled (for $\overline{0}$ example, from a serum sample) and labelled $\stackrel{\odot}{\Phi}$ gentamicin, competition for antibody binding occurs $\stackrel{\overrightarrow{\mathbb{D}}}{\mathbb{Q}}$ and the extent of fluorescence quenching in the $\frac{\varrho}{0}$ unseparated immunoassay incubation mixture, estimated by conventional fluorimetry, may be응 
related to the gentamicin content of the sample by means of a suitably prepared standard curve. The method is termed 'quenching fluoroimmunoassay'.

\section{Material and methods}

\section{REAGENTS}

The preparation of fluoresceinthiocarbamyl gentamicin (FTC-gentamicin) by the reaction of gentamicin with fluorescein isothiocyanate followed by column chromatographic purification on Sephadex G-15 is described in detail elsewhere (Watson et al., 1976a). A stock solution, stored at $4^{\circ} \mathrm{C}$, in $0.05 \mathrm{M}$ sodium carbonate-bicarbonate buffer, $\mathrm{pH} 9.0$, with a content of immunoreactive gentamicin of $3.3 \mathrm{mg} / \mathrm{l}$, as assessed by radioimmunoassay (Watson et al., 1976b), was used.

Anti-gentamicin serum was raised in rabbits by immunisation with conjugates produced by coupling gentamicin to bovine serum albumin by the carbodiimide method (Watson et al., 1976b). Primary immunisation was carried out by injection at multiple intradermal sites of $0.1 \mathrm{mg}$ of the immunogen in $1 \mathrm{ml}$ of an emulsion of equal parts by volume of water and Freund's complete adjuvant. Six weeks later, a booster injection was administered in the same way. Bleeds were taken two weeks after the booster injection and the sera were characterised for FTC-gentamicin binding capacity by means of antibody dilution curves based on fluorescence quenching or fluorescence polarisation (Watson et al., 1976a) measurements. Animals showing satisfactory response were bled at weekly intervals thereafter until the binding capacity of the antiserum obtained had fallen to an unacceptable level, when a further booster injection was given. Antiserum used in the experiments described was from a single animal.

Sodium phosphate buffer, $0.1 \mathrm{M}, \mathrm{pH} 7 \cdot 5$, was employed in all experiments. Mechanical hand pipettes with disposable tips, and disposable plastic test tubes, were used.

\section{FLUORIMETRY}

Measurements were made in an Aminco-Bowman spectrophotofluorimeter with xenon arc lamp source, using standard $1 \times 1 \mathrm{~cm}$ glass cells. The excitation monochromator was set at $495 \mathrm{~nm}$ and the emission monochromator at $540 \mathrm{~nm}$. During operation the overall response of the instrument was frequently checked by recording the signal from a standard fluorescent block (Block 2 from Set 8FS, Starna Ltd, Queens Road West, London E13 0PA) and adjusting the instrumental sensitivity as necessary to obtain a predetermined standard signal level. In this way, variations in response, chiefly attributable to fluctuations in lamp output, were compensated.

ANTIBODY DILUTION CURVE

Doubling dilutions in buffer of anti-gentamicin serum were prepared. Aliquots $(1 \mathrm{ml})$ were pipetted into two series of tubes. To each tube of one series was added 0.5 ml of a 1:200 dilution in buffer of the stock FTC-gentamicin solution and the contents were vortex mixed. To each tube of the other series was added $0.5 \mathrm{ml}$ of buffer and the contents were vortex mixed. This latter series served for estimation of the fluorescence blank signal contributed by the intrinsic fluorescence of the antiserum itself.

After incubation at room temperature for any convenient period longer than 5 minutes to ensure immunochemical equilibration, the fluorescence signals of the test mixtures and blanks were measured in the fluorimeter. The corresponding blank signal was subtracted from the total signal of each test mixture.

\section{QUENCHING FLUOROIMMUNOASSAY METHOD}

Serum samples $(50 \mu \mathrm{l})$ were initially diluted $1: 50$ in buffer. Standards were prepared by adding gentamicin reference solution (Nicholas Laboratories) to diluted pooled normal human serum so as to provide solutions equivalent to serum samples of original gentamicin content varying from 0.25 to $32 \mathrm{mg} / \mathrm{l}$, diluted $1: 50$ in buffer.

Aliquots $(0.5 \mathrm{ml})$ of the diluted samples or standards were pipetted in duplicate into two series of tubes. To each tube of one series was then added $0.5 \mathrm{ml}$ of a 1:200 dilution in buffer of the stock FTC-gentamicin solution. After vortex mixing, $0.5 \mathrm{ml}$ of a $1: 80$ dilution in buffer of anti-gentamicin serum was added to each tube and the contents were immediately vortex mixed again. To each tube of the other series was added $1 \mathrm{ml}$ of buffer and the contents were vortex mixed. This latter series served for estimation of the fluorescence blank signals contributed by the intrinsic fluorescence of the serum samples or standards themselves.

The assay mixtures and blanks were incubated at room temperature for any convenient period longer than 5 minutes (typically 15 minutes to 2 hours) to ensure immunochemical equilibration. After incubation, the fluorescence signals of the assay mixtures and blanks were measured in the fluorimeter. The corresponding blank signal was subtracted from the total signal of each assay mixture. (The intrinsic fluorescence of the antiserum makes a constant small contribution to the total signal of each assay mixture and therefore need not be corrected.) 


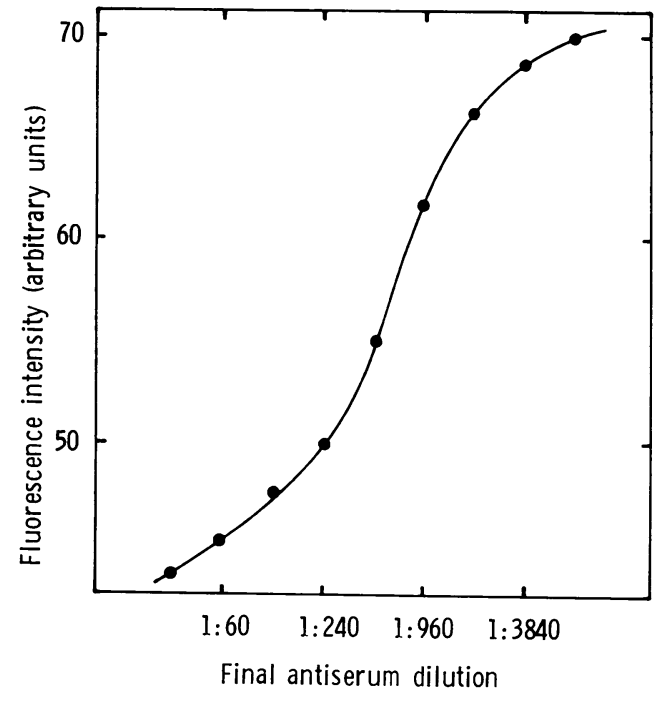

Fig. 1 Antibody dilution curve.

POLARISATION FLUOROIMMUNOASSAY METHOD The method was as described elsewhere (Watson et al., 1976a), apart from the modification of reagent concentrations to suit the different antiserum preparation used.

\section{BIOASSAY}

Results of plate diffusion bioassay of patient serum samples were kindly made available by the routine assay service, Department of Bacteriology, St. Bartholomew's Hospital.

\section{Results}

\section{ANTIBODY DILUTION CURVE}

The anti-gentamicin serum was characterised, and optimum assay conditions were established, by construction of an antibody dilution curve (Fig. 1). A final antiserum dilution of 1:240 was chosen for the quenching fluoroimmunoassay, representing a compromise between the greater assay precision expected from a larger overall quenching effect and the lower assay sensitivity expected at higher antiserum concentration. Although the results presented in Fig. 1 were obtained with antiserum from a single animal, it has been shown that all 13 immunised rabbits produced antiserum giving a similar quenching effect, albeit with different FTC-gentamicin binding capacity.

STANDARD CURVE

A typical standard curve (Fig. 2) covers a range corresponding to about $25 \%$ change in the observed fluorescence signal of FTC-gentamicin. Standard curves produced over a 10 -month period show no significant deterioration, indicating excellent shelf life of FTC-gentamicin.

\section{PRECISION}

The gentamicin reference solution was added to pooled normal human serum (a different batch from that used for preparation of assay standards) so as to provide for samples with the equivalent of $2 \cdot 5$, 5.0 , and $10.0 \mathrm{mg} / \mathrm{l}$ serum gentamicin content. Within-assay precision was assessed by measuring each sample 20 times, giving coefficients of variation of $3.0,5 \cdot 3$, and $6.5 \%$, respectively, at these concentrations. For estimation of between-assay precision, aliquots of the samples were stored frozen until required. Each sample was measured in 20 independent assays, giving mean results of 2.55 , $5 \cdot 15$, and $10 \cdot 17 \mathrm{mg} / \mathrm{l}$ gentamicin with coefficients of variation of $4.9,4.9$, and $11.0 \%$, respectively.

\section{ACCURACY}

Accuracy was tested by recovery experiments in which the gentamicin reference solution was added to 20 different individual gentamicin-free human serum samples, diluted in buffer, so as to give the equivalent of 1:50 initially diluted samples of $2 \cdot 5$, 5.0 , and $10.0 \mathrm{mg} / \mathrm{l}$ original gentamicin content. Assay of these samples gave mean results of $2 \cdot 46$, $5 \cdot 15$, and $9.89 \mathrm{mg} / \mathrm{l}$ gentamicin with coefficients of variation of $9 \cdot 4,5 \cdot 8$, and $11 \cdot 1 \%$, respectively.

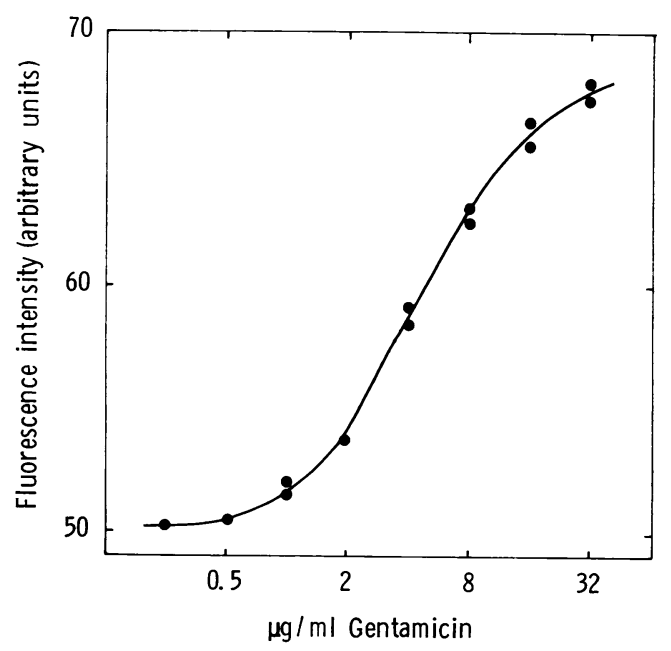

Fig. 2 Gentamicin quenching fluoroimmunoassay standard curve. 


\section{SPECIFICITY}

Various antibiotics were added to pooled normal human serum to give the equivalent of $5.0 \mathrm{~g} / \mathrm{l}$ concentration, and these samples were assayed according to the usual procedure. Of the aminoglycosides, amikacin, kanamycin, neomycin, and streptomycin showed no evidence of cross-reaction with the antiserum, while tobramycin showed very slight, and clinically entirely insignificant, activity equivalent to no more than $0.006 \%$ by weight of that of gentamicin. Other antibiotics found to show no cross-reactivity were ampicillin, benzyl penicillin, carbenicillin, cefazolin, cephalexin, cephaloridine, cephalothin, chloramphenicol, clindamycin, cloxacillin, flucloxacillin, 5-fluorocytosine, fusidic acid, lincomycin, methicillin, and vancomycin.

\section{PATIENT SAMPLES}

Serum samples from patients receiving gentamicin therapy ( 29 peak samples, 20 trough samples) were assayed by the quenching fluoroimmunoassay method. Measurements on the same assay mixtures were then performed in a polarisation fluorimeter so that gentamicin estimations might also be made by the polarisation fluoroimmunoassay method. Bioassays were performed in an independent laboratory.

Figure 3 shows the correlation between the two different fluoroimmunoassay methods (49 samples). The least squares regression of the quenching fluoroimmunoassay results $(y)$ on the polarisation fluoroimmunoassay results $(x)$ is characterised by

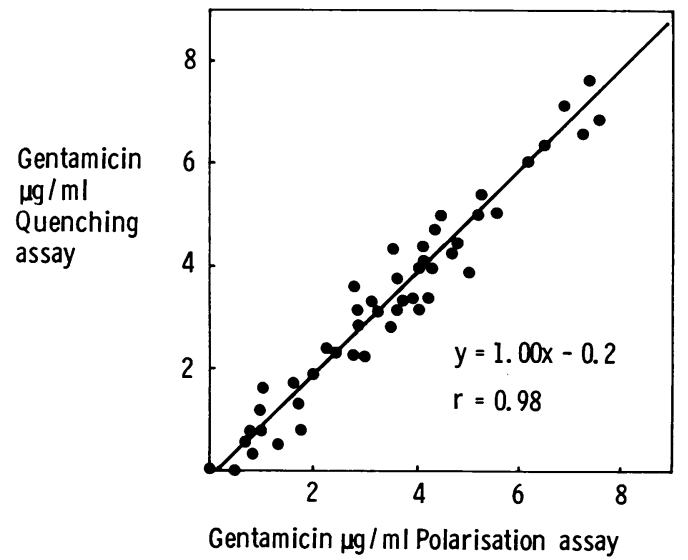

Fig. 3 Correlation between gentamicin levels in 49 patient serum samples determined by quenching fuoroimmunoassay and polarisation fuoroimmunoassay, showing the least squares regression line of quenching fluoroimmunoassay results on polarisation fluoroimmunoassay results.

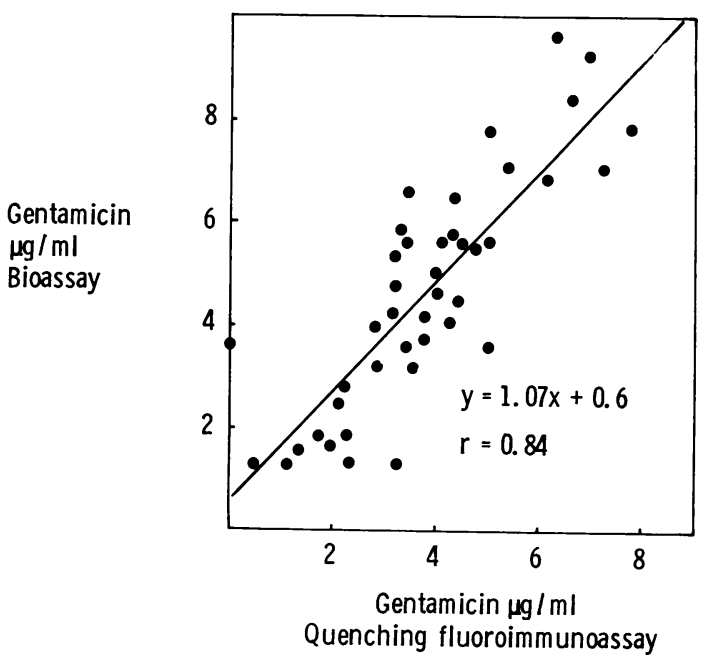

Fig. 4 Correlation between gentamicin levels in 44 patient serum samples determined by bioassay and quenching fluoroimmunoassay, showing the least squares regression line of bioassay results on quenching fluoroimmunoassay results.

the equation $y=1.00 x-0.2$ (units: $\mathrm{mg} / \mathrm{l}$ serum gentamicin), and the correlation coefficient ( $r$ ) takes the value 0.98 .

The bioassay was sensitive to $1.25 \mathrm{mg} / \mathrm{l}$ serum gentamicin, and five trough samples reported as below this limit gave consistent results by quenching fluoroimmunoassay. The correlation between bioassay and quenching fluoroimmunoassay of the remaining 44 samples is shown in Figure 4. The least squares regression of bioassay results $(y)$ on quenching fluoroimmunoassay results $(x)$ is given by $y=1.07 x+0.6, r=0.84$.

Fluorescence blank signals from serum samples were found to vary from about $3 \%$ of the total signal of assay mixtures for normal sera to as much as $15 \%$, notably with visually turbid patient samples (and presumably attributable in such cases to light scattering rather than genuine fluorescence).

In 24 of the assayed patient samples, creatinine levels above the upper normal limit of $120 \mu \mathrm{mol} / \mathrm{l}$ $(1.4 \mathrm{mg} / 100 \mathrm{ml})$ indicated impaired renal function, and 16 of these showed levels in excess of 500 $\mu \mathrm{mol} / 1(5.7 \mathrm{mg} / 100 \mathrm{ml})$, the highest being 1110 $\mu \mathrm{mol} / 1(12.6 \mathrm{mg} / 100 \mathrm{ml})$. However, serum blank signals were found to be unrelated to creatinine level, and no difficulty was encountered in the quenching fluoroimmunoassay of these samples.

Although the present results were obtained using a spectrophotofluorimeter equipped with monochromators and a xenon arc lamp source, it has been shown that measurements may alternatively be made 
using simpler filter fluorimeters with mercury arc lamp source, selecting the $435 \mathrm{~nm}$ group of lines for excitation. If a mercury source is used, samples from cases of impaired renal function may show increased fluorescence blank levels, but not to an extent liable to affect accuracy.

Optical densities $(1 \mathrm{~cm})$ of 40 of the patient samples (20 peak samples, 20 trough samples) and of the pooled normal serum used for preparation of assay standards were measured at the final assay dilution of 1:150 at wavelengths of 495 and $435 \mathrm{~nm}$. Inner filter effects due to attenuation of the exciting light beam by the intrinsic light absorbance of serum were estimated theoretically, making the simplifying assumption that observed fluorescence originates from the centre of the fluorimeter cell. For measurements made using cells of $1 \mathrm{~cm}$ light path, as in the experiments described, less than $2.5 \%$ error in the total fluorescence signal of FTC-gentamicin determined in the presence of a patient serum sample, relative to the signal in the presence of the pooled normal serum, would be expected if the difference in optical density $(1 \mathrm{~cm})$ between the two solutions was less than 0.022 . This was found to be the case for all patient samples at $495 \mathrm{~nm}$, and for 37 of the 40 samples at $435 \mathrm{~nm}$. Commonly encountered levels of haemolysis or turbidity present no problem in this respect. For measurements made using cells of $0.4 \mathrm{~cm}$ excitation beam light path, the corresponding maximum optical density $(1 \mathrm{~cm})$ difference for less than $2.5 \%$ error relative to the pooled normal serum would be 0.055 . This accounted for all patient samples at $435 \mathrm{~nm}$.

\section{Discussion}

The results presented show that, given due attention to precision in pipetting and fluorimetry, the quenching fluoroimmunoassay method described gives reliable estimations of serum gentamicin levels. Comparison with published data indicates that precision and accuracy are better than those of most bioassays (Reeves and Bywater, 1975), at least as good as adenylylating radioenzymatic assays (Smith et al., 1972; Phillips et al., 1974; ten Krooden and Darrell, 1974; Broughall and Reeves, 1975) and similar to acetylating radioenzymatic assays (Broughall and Reeves, 1975; Stevens et al., 1975), radioimmunoassays (Mahon et al., 1973; Berk et al., 1974; Stevens et al., 1975; Broughton and Strong, 1976; Watson et al., 1976b), and polarisation fluoroimmunoassay (Watson et al., 1976a). At all three gentamicin levels tested, assay accuracy falls within statistical limits classed by Reeves and Bywater (1975) as 'good' and of real value in monitoring and controlling gentamicin therapy.

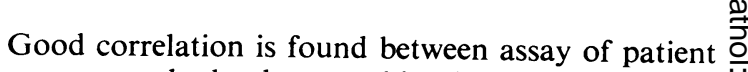
serum samples by the quenching fluoroimmunoassay and the polarisation fluoroimmunoassay method $\stackrel{\mathcal{O}^{9}}{+}$ which has been previously shown (Watson et al., 을 1976a) to correlate with radioimmunoassay and bioassay. The correlation between quenching fluoro- $\frac{\bar{T}}{\vec{D}}$ immunoassay and bioassay of patient samples is $\stackrel{\mathbb{Q}}{\mathscr{Q}}$ considered satisfactory, given the recognised inaccuracy of the bioassay method.

Three main potential sources of inaccuracy in the quenching fluoroimmunoassay may be identified and are discussed individually below.

First, the method is based on detection of relatively small differences in the fluorescence of FTCgentamicin which are comparable in size with the of intrinsic fluorescence blank signals of serum samples. The accuracy of the described blank correction procedure was confirmed, however, by recovery 을 experiments and by the good correlation with the polarisation fluoroimmunoassay of patient samples.

Secondly, it is well known that fluorimetric assay methods are often compromised by high serum blank signals in cases of impaired renal function. Gentamicin assays are frequently requested in such cases as a guide to correct adjustment of dosage to allow for a reduced clearance rate. Creatinine levels in the assayed patient samples indicated severe renal impairment in many cases, yet, in the quenching fluoroimmunoassay system described, no abnormal serum blank signals or other difficulties were encountered. This observation is probably attributable to the $495 \mathrm{~nm}$ excitation wavelength used, which is longer than that required by most fluorimetric methods and less likely to excite intrinsically fluorescent components of serum.

Thirdly, serum samples display intrinsic light absorbance which will attenuate the intensities of $\delta$ the exciting and (usually to a lesser extent) emitted light beams within the fluorimeter cell. This is the so called inner filter effect (Udenfriend, 1969). Any difference between the intrinsic absorbance of a serum sample and that of the pooled normal serum used for preparation of assay standards will give rise to spurious quenching or enhancement of the fluorescence of FTC-gentamicin when measured in an assay mixture containing the serum sample, relative to that measured in a standard assay mixture containing the pooled normal serum. It is essential for the accuracy of the method that such effects be small compared with other sources of error. The results of recovery experiments, and the good correlation with the polarisation fluoroimmunoassay method (which is not subject to inner filter effect interference) show this to be the case in practice, even for patient sera from cases of severe renal impairment. Since all patient samples examined were 
shown to differ in optical density $(1 \mathrm{~cm})$ relative to the pooled normal serum by less than 0.022 (less than $2.5 \%$ predicted error in the total fluorescence of FTC-gentamicin) at $495 \mathrm{~nm}$ when measured at the final assay dilution, it is suggested that this criterion may be used as a simple test of the acceptability of any sample for measurements made in $1 \times 1 \mathrm{~cm}$ cells with $495 \mathrm{~nm}$ excitation wavelength. Only sera with obviously highly abnormal appearance (intense colour, especially yellow or orange, or excessive turbidity) will fail this test.

Any modern fluorimeter should be suitable for the quenching fluoroimmunoassay. If a filter fluorimeter with mercury arc lamp source is used, care must be taken to control inner filter effects because of the greater light absorbance of serum at $435 \mathrm{~nm}$ than at $495 \mathrm{~nm}$. The results of optical density measurements of patient serum samples at $435 \mathrm{~nm}$ indicate that in such a case an exciting light beam path length of $0.4 \mathrm{~cm}$ would be acceptable at the final serum sample dilution of $1: 150$ used in the described assay method. Fluorimeter cells of $0.4 \times 1$ $\mathrm{cm}$ dimensions are readily available commercially. Suitable assay conditions may be easily established empirically for any combination of fluorimeter, anti-gentamicin serum, and FTC-gentamicin preparation by first determining the concentration of FTC-gentamicin required to produce a fluorescence signal of sufficient stability, then constructing an antibody dilution curve to find the optimum antiserum dilution. Finally, the initial dilution of serum samples should be fixed so as to obtain the desired sensitivity.

The mechanism of the fluorescence quenching observed when FTC-gentamicin is bound by antigentamicin serum is not known. The results of immunisation of several animals show, however, that there is every reason to be optimistic that the quenching effect is a property of at least the majority of anti-gentamicin sera.

The quenching fluoroimmunoassay of gentamicin is more rapid and technically simpler than any method of comparable reliability. The required serum sample size is small enough to cope with most eventualities. Because FTC-gentamicin has practically indefinite shelf life and may be easily and economically prepared in large quantity (contrast, for example, 125I-labelled gentamicin), the cost of the labelled material can be essentially negligible. The only significant recurrent cost of routine assays might be that involved in raising or possibly purchasing anti-gentamicin serum. The only capital equipment required is a conventional fluorimeter.

\section{References}

Berk, L. S., Lewis, J. L., and Nelson, J. C. (1974). Onehour radioimmunoassay of serum drug concentrations, as exemplified by digoxin and gentamicin. Clin. Chem., 20, 1159-1164.

Broughall, J. M. and Reeves, D. S. (1975). The acetyltransferase enzyme method for the assay of serum gentamicin concentrations and a comparison with other methods. J. clin. Path., 28, 140-145.

Broughton, A. and Strong, J. E. (1976). Radioimmunoassay of iodinated gentamicin. Clin. chim. Acta, 66, 125-129.

Mahon, W. A., Ezer, J., and Wilson, T. W. (1973). Radioimmunoassay for measurement of gentamicin in blood. Antimicrob. Agents Chemother., 3, 585-589.

Noone, P., Pattison, J. R., and Samson, D. (1971). Simple, rapid method for assay of aminoglycoside antibiotics. Lancet, 2, 16-19.

Phillips, I., Warren, C., and Smith, S. E. (1974). Serum gentamicin assay: a comparison and assessment of different methods. J. clin. Path., 27, 447-451.

Reeves, D. S. (1972). Assay of gentamicin (Letter). Lancet, 2, 1369-1370.

Reeves, D. S. (1974). Gentamicin therapy. Brit. J. Hosp. Med., 12, 837-850.

Reeves, D. S. and Bywater, M. J. (1975). Quality control of serum gentamicin assays-experience of national surveys. J. antimicrob. Chemother., 1, 103-116.

Smith, D. H., Van Otto, B., and Smith, A. L. (1972). A rapid chemical assay for gentamicin. New Engl. J. Med., 286, 583-586.

Stevens, P., Young, L. S., and Hewitt, W. L. (1975). Radioimmunoassay, acetylating radio-enzymatic assay, and microbioassay of gentamicin: a comparative study. J. Lab. clin. Med., 86, 349-359.

ten Krooden, E. and Darrell, J. H. (1974). Rapid gentamicin assay by enzymic adenylylation. J. clin. Path., 27, 452-456.

Udenfriend, S. (1969). Fluorescence Assay in Biology and Medicine, Vol. II, pp. 182-185. Academic Press, New York.

Watson, R. A. A., Landon, J., Shaw, E. J., and Smith, D. S. (1976a). Polarisation fluoroimmunoassay of gentamicin. Clin. chim. Acta, 73, 51-55.

Watson, R. A. A., Shaw, E. J., and Edwards, C. R. W. (1976b). A ${ }^{125}$ I-based radioimmunoassay for serum gentamicin. In Chemotherapy, Vol. 2, edited by J. D. Williams and A. M. Geddes, pp. 107-110. Plenum Press, New York and London. 